Supporting Information: Environmental Science and Technology

November 19, 2007

\title{
Iron Isotope Fractionation by Biogeochemical Processes in Mine Tailings
}

\author{
Roger B. Herbert Jr. ${ }^{1 *}$, Axel Schippers ${ }^{2}$ \\ ${ }^{1}$ Department of Earth Sciences, Uppsala University, Villavägen 16, 75236 Uppsala, Sweden \\ ${ }^{2}$ Section Geomicrobiology, Federal Institute for Geosciences and Natural Resources (BGR), \\ Stilleweg 2, 30655 Hannover, Germany \\ * Correspondences should be directed to first author \\ Telephone: +46184712266 \\ Fax: +4618 551124 \\ Email: roger.herbert@geo.uu.se
}

Supporting Information contains 12 pages, including 4 Tables and 2 Figures. 


\section{Subsurface hydrology}

The Kristineberg mine tailings deposit (Impoundment 1) covers an area of 1.2 ha and has an average thickness of 6 to $8 \mathrm{~m}$. In 1996, half of the mine tailings were remediated with the installation of a $0.3 \mathrm{~m}$ sealing layer, consisting of compacted clay-rich glacial till, which was covered with a $1.8 \mathrm{~m}$ protective layer of uncompacted glacial till. In the area of the deposit where samples were collected for this study, the depth to the water table, as indicated by nearby groundwater wells (see 1 for details), was more than one meter below the lower boundary of the soil cover. However, the unoxidized tailings are water-saturated due to the fine grain-size of the tailings and capillary rise from the water table. The water table may rise into the oxidized tailings during periods of intense rainfall or snowmelt. This stratigraphy is illustrated in Figure S-1.

The sealing layer has a low hydraulic conductivity, on the order of $10^{-9} \mathrm{~m} / \mathrm{s}$, which limits the annual percolation through the sealing layer to roughly $100 \mathrm{~mm}$ (2). Water percolating through the sealing layer will flow vertically through the unsaturated tailings until the water table is intercepted. Directly below the water table, the groundwater flow direction is also vertical, but with increasing depth there will be an increase in the horizontal flow component and a decrease in the vertical flow component (see Figure S-1). Below a specific depth, which is a function of the relative intensity of the flow components, groundwater flow in the tailings is approximately horizontal. Although the groundwater flow field components have not been studied in detail at the Kristineberg site, it can be assumed that pore water flow through the oxidized tailings and upper meter of the unoxidized tailings is primarily vertical and pore water composition will be influenced by biogeochemical processes in the overlying tailings. Below this depth, where the horizontal flow component becomes increasingly dominant, pore water composition is more influenced by lateral flow from other areas of the impoundment.

\section{Chemical composition of tailings}

Ascorbate-extractable Fe. Metals bound in 'reactive metal oxides' can be extracted using a mild reductant such as ascorbic acid (3); this method will not significantly dissolve crystalline / resistant iron oxides, iron monosulfides, or silicates such as chlorite. For extraction, $20 \mathrm{~mL}$ ascorbate solution $\left(5 \% \mathrm{NaHCO}_{3}, 5 \%\right.$ trisodium citrate, and $2 \%$ ascorbic acid in deaerated water, final $\left.\mathrm{pH} 8\right)$ was added to a $1 \mathrm{~g}$ wet sample, and the mixture was shaken overnight in a nitrogen atmosphere. 
After agitation, the aqueous phase is filtered through a $0.45 \mu \mathrm{m}$ membrane filter, acidified with suprapur $^{\mathrm{TM}} \mathrm{HCl}$, and analyzed by ICP-MS for Fe.

Total elemental composition. The bulk Fe composition of tailings samples also analyzed for stable iron isotope composition was determined from the acid extraction of samples and microwave digestion. The microwave-assisted digestion was performed in closed Teflon vessels (125 ml) using an aqua regia/HF mixture (8+2) using $200 \mathrm{mg}$ of material. Digestion time was $1 \mathrm{~h}$ with a digestion temperature of $>130^{\circ} \mathrm{C}$ (monitored as temperature of external surface of test vessel). Samples were gently ground prior to digestion. This method is very effective in providing quantitative Fe recovery from Si-containing or Si-based matrices. The results of these analyses are provided in Table 1 and Table S-4.

For the determination of total sulfur concentrations in the solid tailings material, dried samples $\left(50^{\circ} \mathrm{C}\right)$ were leached with $7 \mathrm{M}$ nitric acid in a sealed teflon container in a microwave oven. For the determination of total major metal concentrations, independently of stable iron isotope analyses, dried samples $\left(50^{\circ} \mathrm{C}\right)$ were fused with lithium metaborate and dissolved in dilute nitric acid. Elemental concentrations in solutions were determined by ICP-MS. The total chemical analyses were performed by Analytica $\mathrm{AB}$ in Luleå, Sweden. The results from these analyses are presented in Table S-1; results for Fe from this analytical method are also provided in Table 1. A comparison of these two analytical techniques indicates that the fusion method often yields slightly greater Fe concentrations, but that the difference in values lies within the analytical uncertainty.

\section{X-ray diffractometry}

X-ray diffraction analyses were performed using a Siemans D-5000 diffractometer with a BraggBrentano configuration. The diffractometer was equipped with a variable divergence slit, a $1 \mathrm{~mm}$ detector slit, a $0.2 \mathrm{~mm}$ anti-scatter slit, a graphite monochromator, and a $\mathrm{Cu} \mathrm{K} \alpha \mathrm{X}$-ray source. Powder samples were scanned from $5^{\circ} 2 \Theta$ to $80^{\circ} 2 \Theta$ at a scan rate of $10^{\circ} 2 \Theta$ per minute; final diffractograms are the product of five cumulative scans. Mineralogy was determined by comparing diffractograms with powder diffraction standards (4). 


\section{Quality control}

Extraction with hydroxylamine hydrochloride. In order to assess the selectivity of the hydroxylamine hydrochloride (HAH) extraction technique, the following four samples were extracted: 1) goethite ( $\alpha-\mathrm{FeOOH}$; synthesized according to 5, p. 489), 2) pyrite (grain-size 125 $250 \mu \mathrm{m}$, obtained commercially), 3) chloritized biotite (grain-size 40 - $71 \mu \mathrm{m}$; sample 19630491 obtained from the Museum of Natural History in Stockholm), and 4) waste rock (ground to $<250$ $\mu \mathrm{m}$ ) from the Ljusnarsberg waste rock dump in central Sweden. X-ray diffractometry (XRD) was used to confirm the mineralogy of the samples (see above); the goethite, pyrite, and chlorite biotite samples were identified as pure phases, within the detection limit of the XRD technique (generally $\sim 5$ volume \%). X-ray diffractometry indicated (Fig. S-2) that the waste rock sample contained the secondary Fe minerals jarosite $\left[\mathrm{KFe}_{3}\left(\mathrm{SO}_{4}\right)_{2}(\mathrm{OH})_{6}\right]$ and goethite, as well as the minerals biotite (annite), hornblende and gypsum (also a secondary mineral).

For the four samples used to test the selectivity of the HAH extraction, the total Fe and HAHextractable iron content were determined. As shown in Table S-4, the HAH extraction technique removes $>90 \%$ of bulk $\mathrm{Fe}$ in goethite, $<1 \%$ of bulk $\mathrm{Fe}$ in pyrite, $\sim 40 \%$ of bulk Fe in chloritized biotite, and $\sim 60 \%$ of bulk Fe from the waste rock sample. As shown in Fig. S-2, the treatment of the waste rock sample with HAH resulted in the dissolution of all jarosite and goethite; gypsum was probably reprecipitated after sample treatment. However, the Fe concentration of specific minerals in the waste rock is unknown, so it is not possible to determine if some of the HAH-extractable Fe is also derived from Fe silicates.

Assessment of fractionation during extraction. In order to determined if $\mathrm{Fe}$ isotope fractionation occurs during $\mathrm{HAH}$-extraction, $\delta^{56} \mathrm{Fe}$ values were obtained from the HAH extraction and total extraction of the goethite. The iron isotope analyses of synthetic goethite (see Table S-4) following $\mathrm{HAH}$ and total extraction indicates that these extraction methods yield similar $\delta^{56} \mathrm{Fe}$ values $(0.47$ and $0.49 \%$, respectively); therefore, little isotopic fractionation is expected using hydroxylamine hydrochloride under the conditions applicable in this study.

Analytical uncertainty. Iron isotope measurements are reported with an uncertainty of two standard deviations, which is calculated from the propagation of errors associated with instrumental error, analytical reproducibility, and sample handling and extraction (external errors). Repeat 
measurements were performed for all multi-collector ICP-MS analyses to assess instrumental error; reported standard deviations reflect the independent determination of two MC-ICP-MS measurements. The commercial laboratory has assessed reproducibility through the analysis of synthetic solutions (e.g. commercially available stock solution), yielding a long-term reproducibility $(\mathrm{n}>70)$ of $0.024 \%$ o expressed as 1 sigma for $\delta^{56} \mathrm{Fe}$ in simple samples. However, the reproducibility for the entire analytical procedure (including sample preparation) is as a rule better then $0.050 \%$ o when $\mathrm{Fe}$ concentration is not a limiting factor. In order to assess extraction reproducibility and sample variability, approximately one third of all samples were analyzed in duplicate. The mean standard deviation of duplicate samples provides an estimate of the external error, which averaged 0.034\%. The method for determining the propagation of errors was used to obtain a total uncertainty for these three independent sources of error, resulting in values ranging from 0.12 to 0.18\%. A certified reference material, aside from IRMM-014 that is used for instrumental massbias normalization, is not available for stable iron isotope analyses, so it was not possible to assess the accuracy of the analytical procedures. However, during method development the commercial laboratory has assured that, by applying digestion and separation procedures to IRMM-014, they do not introduce measurable artificial fractionation.

Quality control by mass balance. The quality of the Fe and stable iron isotope analyses performed in this study were evaluated using mass balance calculations. For the calculations, Fe analyses and $\delta^{56} \mathrm{Fe}$ values were determined for samples treated with the HAH extraction and a total extraction. The residual from the $\mathrm{HAH}$ extraction was subsequently analyzed for total $\mathrm{Fe}$ and $\delta^{56} \mathrm{Fe}$. Using the results from the analyses given above, a $\delta^{56} \mathrm{Fe}$ value for the bulk sample is calculated and compared to the measured value according to the following mass balance:

$\partial^{56} F e_{\text {total-calculated }} \approx \frac{\partial^{56} F e_{H A H} X_{H A H}+\partial^{56} F e_{\text {residual }} X_{\text {residual }}}{X_{H A H}+X_{\text {residual }}}$

where $\mathrm{X}$ is the mole fraction of Fe from each the HAH extraction and the residual fraction; $\mathrm{X}_{\mathrm{HAH}}+$ $\mathrm{X}_{\text {residual }}=1$. The results of the mass balance calculations (Table S-4) indicate a certain degree of discrepancy between the calculated bulk $\delta^{56} \mathrm{Fe}$ values and the measured values. The error lies in the range $0.34-0.63 \%$, and is produced by the combined effect of the relatively high uncertainty in the Fe analyses ( $\pm 16 \%$ according to laboratory), the uncertainty in the stable isotope ratio measurements, and sample heterogeneity. Since HAH extractions and total extractions were 
performed on unique samples, a certain degree of variation among samples is expected. Sample heterogeneity is exemplified in the results from duplicate samples, where Fe concentrations are generally quite similar but can nevertheless differ by up to $1.2 \mathrm{wt} \%$ (Table 1 ); duplicate $\delta^{56} \mathrm{Fe}$ values are also generally very similar but differences up to $0.12 \%$ are observed (Table 2 ). Additional sources of error include inadequate sample washing and loss of fines during sample washing, prior to determination of residual fraction after HAH-extraction. Also, incomplete dissolution of bulk samples with acidic microwave dissolution method may lead to underestimation of total Fe concentrations. It is believed that the cumulative effect of all these potential errors has resulted in the mass balance discrepancy; nevertheless, the overall trends in the analytical data support the conclusions drawn by this study.

\section{Calculation of $\delta^{56} \mathrm{Fe}$ value for pyrite}

If it is assumed that the stable iron isotope composition of the tailings below the oxidation zone is dominated by pyrite and Fe silicates (adsorbed Fe accounts for at most $2 \%$ of the total Fe content, Table 1), then the $\delta^{56} \mathrm{Fe}$ value for pyrite can be calculated from the following mass balance relationship:

$\delta^{56} \mathrm{Fe}_{\text {pyrite-unox }}=\frac{\delta^{56} \mathrm{Fe}_{\text {bulk-unox }}-\delta^{56} \mathrm{Fe}_{\text {res-oxid }} \mathrm{X}_{\text {res-oxid }}}{\mathrm{X}_{\text {pyrite-unox }}}$

where $\mathrm{X}_{\text {res-oxid }}$ is the average mole fraction of $\mathrm{Fe}$ in the residual material after HAH-extraction, in the oxidized tailings $(0.12$, equal to $2.4 \mathrm{wt} \%$ / $19.7 \mathrm{wt} \%$; data from Table 1 and $\mathrm{S}-1), \mathrm{X}_{\text {pyrite-unox }}$ is the average mole fraction of $\mathrm{Fe}$ in pyrite from the unoxidized tailings, equal to $1-\mathrm{X}_{\text {res-oxid }}$, and $\delta^{56} \mathrm{Fe}_{\text {bulk-unox }}$ and $\delta^{56} \mathrm{Fe}_{\text {residual-oxid }}$ are the $\delta^{56} \mathrm{Fe}$ values for the bulk unoxidized tailings (-0.27\%o) and the residual fraction from oxidized tailings (-0.89\%), respectively (Table 2). Based on equation 5, the average $\delta^{56} \mathrm{Fe}$ value for pyrite is $-0.18 \pm 0.17 \%(2 \sigma)$.

\section{References}

(1) Holmström, H.; Salmon, U. J.; Carlsson, E.; Petrov, P.; Öhlander, B. Geochemical investigations of sulfide-bearing tailings at Kristineberg, northern Sweden, a few years after remediation. The Science of the Total Environment 2001, 273, 111-133. 
(2) Höglund, L.O., Herbert, R. (Eds.), Lövgren, L., Öhlander, B., Neretnieks, I., Moreno, L., Malmström, M., Elander, P., Lindvall, M. and Lindström, B. 2004. MiMi-Performance Assessment Main Report, MiMi report 2003:3, MiMi print, Luleå, 345 p.

(3) Ferdelman, T.G.; Church, T.M.; Luther III, G.W. Sulfur enrichment of humic substances in a Delaware salt marsh sediment core. Geochim. Cosmochim. Acta 1991, 55, 979 - 988.

(4) JCPDS, Joint committee on powder diffraction standards, 2001. International centre for diffraction data, Newtown Square, PA.

(5) Cornell, R.M.; Schwertmann, U. The Iron Oxides: Structure, properties, reactions, occurrence and uses. VCH Verlagsgesellschaft mbH, Weinheim, 1996, 573 p. 
Table S-1: Total concentrations (wt $\%$ ) of major elements in mine tailings.

\begin{tabular}{rrrrrrrrrr}
\hline $\begin{array}{r}\text { Depth } \\
(\mathbf{c m})\end{array}$ & $\mathbf{F e}$ & $\mathbf{S}$ & $\mathbf{A l}$ & $\mathbf{C a}$ & $\mathbf{K}$ & $\mathbf{M g}$ & $\mathbf{N a}$ & $\mathbf{S i}$ & $\mathbf{T i}$ \\
\hline 217 & 6.67 & 2.35 & 6.09 & 0.80 & 1.24 & 4.82 & 0.87 & 26.41 & 0.25 \\
223 & 7.06 & 1.89 & 6.88 & 0.35 & 0.88 & 8.26 & 0.19 & 22.06 & 0.18 \\
230 & 6.09 & 8.92 & 4.10 & 4.57 & 0.54 & 6.45 & 0.17 & 19.35 & 0.12 \\
238 & 6.10 & 2.93 & 6.46 & 0.18 & 0.79 & 7.84 & 0.11 & 22.39 & 0.18 \\
243 & 8.92 & 7.34 & 6.35 & 0.50 & 1.06 & 5.74 & 0.69 & 21.71 & 0.21 \\
265 & 11.16 & 10.85 & 6.77 & 0.17 & 0.68 & 7.72 & 0.11 & 17.39 & 0.15 \\
288 & 18.50 & 19.65 & 5.24 & 0.50 & 0.40 & 5.79 & 0.08 & 14.23 & 0.17 \\
306 & 15.39 & 15.10 & 4.90 & 0.74 & 0.33 & 5.34 & 0.10 & 17.72 & 0.23 \\
324 & 19.79 & 22.90 & 5.61 & 0.65 & 0.48 & 5.47 & 0.07 & 10.42 & 0.07 \\
508 & 14.13 & 14.60 & 6.51 & 0.26 & 0.62 & 7.72 & 0.10 & 15.38 & 0.09 \\
524 & 23.50 & 24.70 & 4.38 & 0.45 & 0.39 & 5.45 & 0.08 & 10.10 & 0.08 \\
536 & 18.88 & 19.70 & 4.77 & 1.34 & 0.64 & 5.02 & 0.10 & 12.53 & 0.11 \\
565 & 20.49 & 21.80 & 4.47 & 0.64 & 0.44 & 6.57 & 0.09 & 12.25 & 0.08 \\
590 & 23.29 & 22.50 & 4.72 & 1.05 & 0.43 & 5.51 & 0.09 & 11.13 & 0.09 \\
620 & 21.40 & 20.70 & 4.26 & 1.12 & 0.35 & 6.15 & 0.08 & 11.22 & 0.09 \\
\hline
\end{tabular}

Table S-2: Pore water chemistry presented in Figure 1. Pore water was pressed from tailings from a specific depth interval. The mean depth is plotted on Figure $1 \mathrm{~b}$ and 1c.

\begin{tabular}{ccccccc}
\hline $\begin{array}{c}\text { Depth interval } \\
(\mathrm{cm})\end{array}$ & $\begin{array}{c}\text { Mean depth } \\
(\mathrm{cm})\end{array}$ & $\mathrm{pH}$ & $\begin{array}{c}\text { Eh } \\
(\mathrm{mV})\end{array}$ & $\begin{array}{c}\mathrm{Fe} \\
(\mathrm{mM})\end{array}$ & $\begin{array}{c}\mathrm{S} \\
(\mathrm{mM})\end{array}$ & $\mathrm{Fe}(\mathrm{III}) / \mathrm{Fe}(\mathrm{II})$ \\
\hline $221-225$ & 223.5 & n.a. & n.a. & 4.84 & 21.18 & 0.021 \\
$227-233$ & 230 & 3.11 & 576 & 4.24 & 22.27 & 0.021 \\
$236-241$ & 238.5 & 2.73 & 673 & 1.92 & 24.83 & 0.792 \\
$240-246$ & 243 & 4.64 & 392 & 19.11 & 34.06 & 0.001 \\
$262-268$ & 265 & 4.37 & 506 & 20.07 & 34.16 & 0.019 \\
$285-291$ & 288 & 4.65 & 399 & 9.44 & 23.74 & 0.0010 \\
$321-327$ & 324 & 4.73 & 348 & 4.86 & 19.16 & 0.0002 \\
$505-511$ & 508 & 5.68 & 165 & 7.03 & 21.50 & 0.00001 \\
$521-527$ & 524 & 6.13 & 162 & 5.62 & 21.15 & 0.0001 \\
$533-539$ & 536 & 6.21 & 153 & 7.53 & 21.47 & 0.0001 \\
$562-568$ & 565 & 6.46 & 128 & 8.35 & 22.62 & 0.0001 \\
$587-593$ & 590 & 6.43 & 110 & 9.38 & 22.94 & 0.0001 \\
$617-623$ & 620 & 6.31 & 116 & 9.34 & 23.39 & 0.00004 \\
\hline
\end{tabular}


Table S-3: Number of acidophilic Fe(II)-oxidizing microorganisms in tailings, as determined by MPN method. Tailings from a specific depth interval were first homogenized and then sampled prior to MPN enumeration. The mean depth from the homogenized depth interval is plotted on Figure 1d. n.d. = not detected.

\begin{tabular}{ccc}
\hline Depth interval (cm) & $\begin{array}{c}\text { Mean depth } \\
(\mathrm{cm})\end{array}$ & $\begin{array}{c}\text { Fe(II)-oxiders } \\
\text { Number / g dry w. }\end{array}$ \\
\hline $210-220$ & 215 & 280,000 \\
$220-227$ & 223.5 & 5,700 \\
$227-233$ & 230 & 670 \\
$233-244$ & 238.5 & $6,094,000$ \\
$260-270$ & 265 & n.d. \\
$330-340$ & 335 & n.d. \\
$490-500$ & 495 & n.d. \\
$550-560$ & 555 & n.d. \\
$625-635$ & 630 & n.d. \\
& & \\
\hline
\end{tabular}


Table S - 4: Analytical results used for quality control assessment of the Fe analyses, hydroxylamine hydrochloride $\left(\mathrm{HAH} ; \mathrm{NH}_{2} \mathrm{OH} \cdot \mathrm{HCl}\right)$ extraction, and $\delta^{56} \mathrm{Fe}$ determinations. n.a. = not analyzed. Data on last three lines is used for mass balance calculations, where the propagation of errors is considered in the reported uncertainty values. Fe concentration reported with $\pm 2 \sigma$ uncertainty, where measurement uncertainty $( \pm 16 \%)$ and external error are considered. Fe isotope compositions are reported with $\pm 2 \sigma$ uncertainty, where analytical uncertainty, analytical reproducibility and external errors are considered.

\begin{tabular}{|c|c|c|c|c|c|c|c|}
\hline \multirow[t]{2}{*}{$\begin{array}{c}\text { Sample / } \\
\text { depth }\end{array}$} & \multicolumn{2}{|c|}{$\begin{array}{c}\mathrm{NH}_{2} \mathrm{OH} \cdot \mathrm{HCl} \\
\text { extractable } \mathrm{Fe}\end{array}$} & \multicolumn{2}{|c|}{ Residual $\dagger$} & \multicolumn{2}{|c|}{ Total Fe } & \multirow{2}{*}{$\begin{array}{c}\text { Calculated } \\
\delta^{56} \mathrm{Fe} \ddagger\end{array}$} \\
\hline & $\begin{array}{c}\mathrm{Fe} \\
(\mathrm{wt} \%)\end{array}$ & $\delta^{56} \mathbf{F e}$ & $\begin{array}{c}\mathrm{Fe} \\
(w t \%)\end{array}$ & $\delta^{56} \mathbf{F e}$ & $\begin{array}{c}\mathrm{Fe} \\
(w t \%)\end{array}$ & $\delta^{56} \mathbf{F e}$ & \\
\hline Pyrite & 0.21 & n.a. & n.a. & n.a. & 46.6 & n.a. & -- \\
\hline Biotite & 4.28 & n.a. & n.a. & n.a. & 11.6 & n.a. & -- \\
\hline Goethite & 55.82 & $0.473 \pm 0.123$ & n.a. & n.a. & 60.9 & $0.490 \pm 0.120$ & -- \\
\hline Wst. rock & 13.98 & $-0.59 \pm 0.146$ & n.a. & n.a. & 25.2 & $-0.848 \pm 0.179$ & -- \\
\hline $220-226$ & $2.4 \pm 0.6$ & $0.028 \pm 0.121$ & $2.2 \pm 0.6$ & $-0.959 \pm 0.122$ & $4.9 \pm 0.9$ & $-0.890 \pm 0.120$ & $-0.448 \pm 0.173$ \\
\hline $235-241$ & $2.5 \pm 0.6$ & $0.314 \pm 0.124$ & $2.5 \pm 0.6$ & $-0.814 \pm 0.130$ & $4.3 \pm 0.9$ & $-0.907 \pm 0.159$ & $-0.273 \pm 0.151$ \\
\hline $587-593$ & $4.7 \pm 0.9$ & $-0.246 \pm 0.121$ & $22.0 \pm 3.6$ & $0.118 \pm 0.138$ & $21.0 \pm 3.4$ & $-0.288 \pm 0.121$ & $+0.054 \pm 0.117$ \\
\hline
\end{tabular}

$\uparrow$ This is the residual material remaining after extraction with $1 \mathrm{M} \mathrm{NH}_{2} \mathrm{OH} \cdot \mathrm{HCl}$ in $1 \mathrm{M} \mathrm{HCl}$

$\$ \delta^{56} \mathrm{Fe}$ calculated for the total sample, based on analysis of $\mathrm{HAH}$ - extractable fraction and residual fraction, according to equation $\mathrm{S} 1$ 


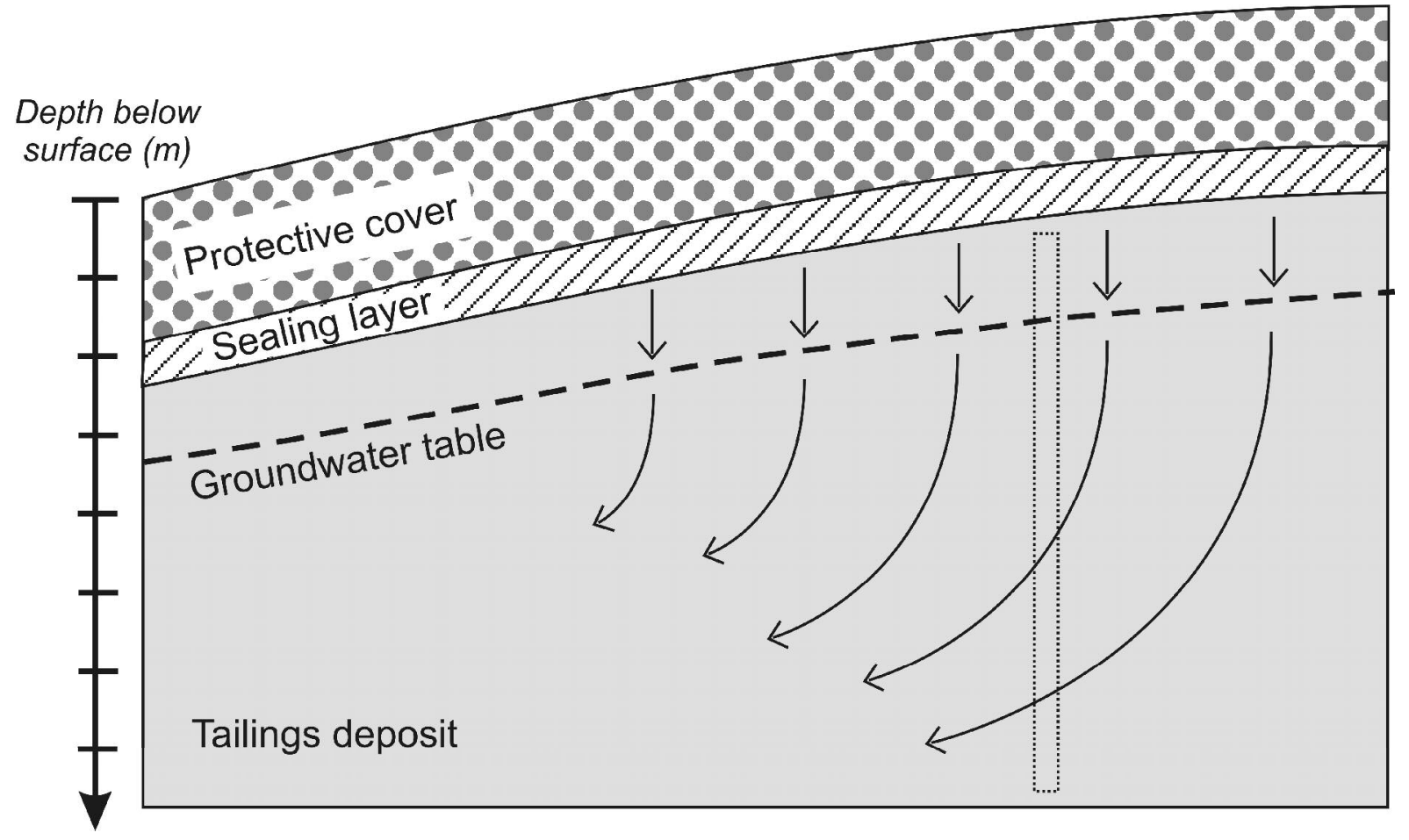

Figure S-1: Schematic diagram showing cross-section of mine tailings deposit and an illustration of the direction of water flow below the sealing layer (arrows). Dotted box indicates that approximate depth interval from which samples in this study were collected. 

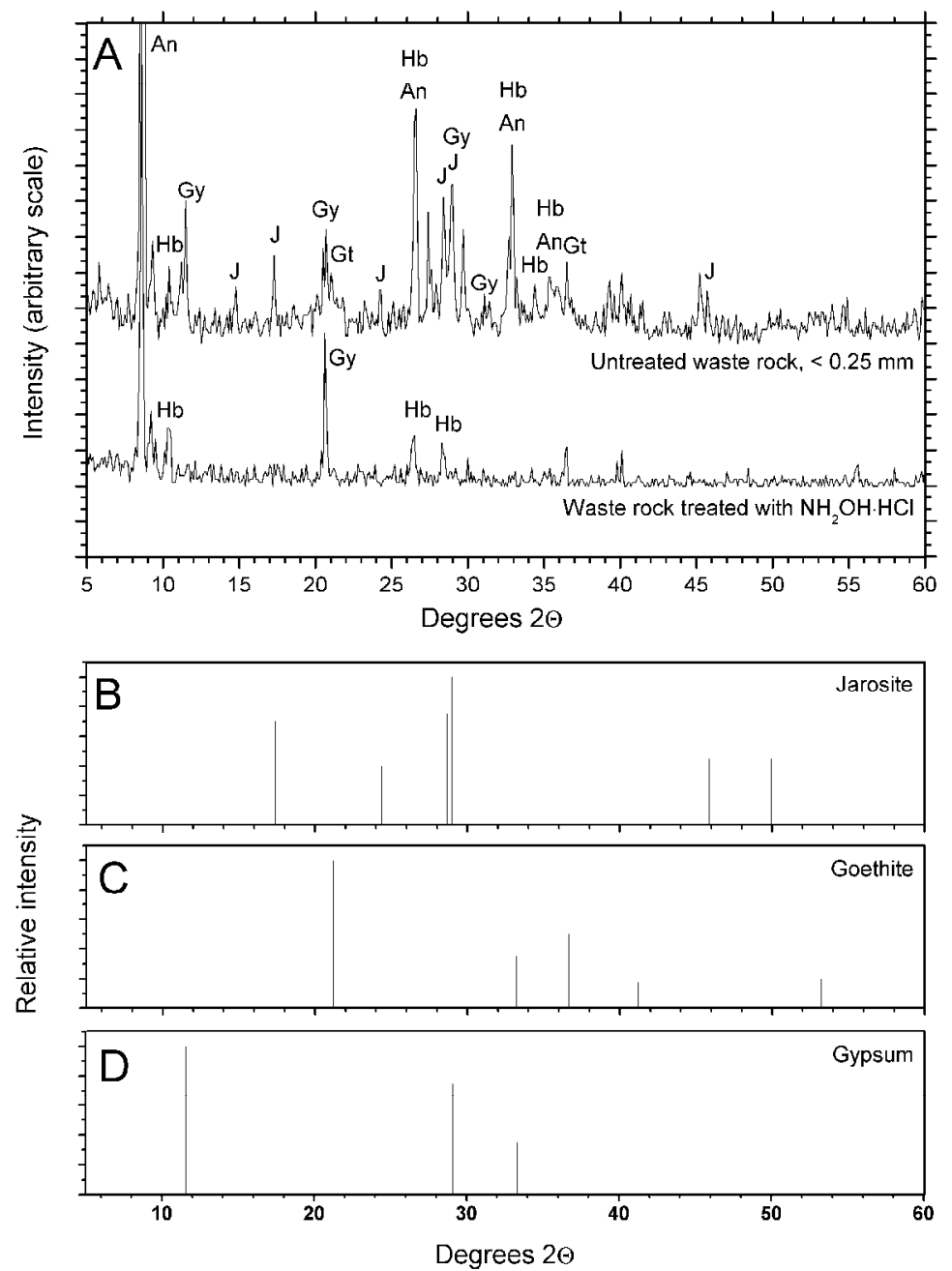

Figure S-2: A) X-ray diffractograms of untreated waste rock $(<0.25 \mathrm{~mm})$ and waste rock extracted with $1 \mathrm{M} \mathrm{NH}_{2} \mathrm{OH} \cdot \mathrm{HCl}$ in $1 \mathrm{M} \mathrm{HCl}$. $\mathrm{Hb}=$ hornblende, $\mathrm{J}=$ potassium jarosite, $\mathrm{Gt}=$ goethite, $\mathrm{An}=$ annite, Gy = gypsum. B) Powder diffraction pattern for seven most prominent diffraction lines for potassium jarosite (2, pattern 22 - 0827). C) Powder diffraction pattern for five most prominent diffraction lines for goethite (2, pattern 29 - 0713). D) Powder diffraction pattern for five most prominent diffraction lines for gypsum $(2$, pattern 33 - 0311). Note that no attempt was made to prepare randomly - oriented XRD samples, so that the intensity of the peaks corresponding to primary silicates (e.g. annite, hornblende) may not be comparable from one diffractogram to another. 